\title{
Research on Practical Teaching Mode of College Advertising Course Fei Teng ${ }^{1}$, Ya Xiao $^{2}$ \\ ${ }^{1}$ Department of Information Engineering,Tangshan Vocational \&Technical College,Tangshan, 063000, China \\ ${ }^{2}$ Department of Media Art, Shijiazhuang Information Engineering Vocational College, Shijiazhuan, 050000,China
}

Keywords: Practical teaching mode; Advertising course; College education

\begin{abstract}
College advertising teaching should envisage the trend of market development and its particularity, on the basis of student-oriented, social demand and graduation direction of students oriented, aiming the high quality and skill practical professional talents training. As a subject with very strong practicality, advertising has many problems, such as teaching idea content is fuzzy, platform of practical teaching is not enough, teachers lack practical experience, teaching methods are outdated, and so on.We should aim to serving society, define the teaching positioning, highlight ability training, build the teaching system; innovate teaching mode, emphasize connotation construction, perfect security system, innovate the modes in demonstration teaching, case teaching, project teaching and discuss teaching.
\end{abstract}

\section{Introduction}

Since reform and opening up, with the fast development of economy and society, advertisement has stepped in an new stage and presented a thriving developing trend. Especially, since 1990th, advertising has being one of the most developing industry in China. Advertising has being playing a very important role in our economy and society, development as one knowledge intensive, technology intensive and talent intensive high-tech industry. The development of the advertising industry has broadened the idea of higher education in the cultivation of applied talents what's more the relevant professional has become popular in current higher education. Along with economic globalization advancement's quickening and new social eco-environment establishing, the need of marketing has strengthened the power of Talent Cultivation in colleges and universities. However, how to cultivate the applied advertisement elite becomes the most important research project in high education.

Modern society is the information intensive society, it is very hard for educator educated all information to educatees, so long as the educatees can not earn all working tech ability from one training. Thus, constantly improving own potential and ability to adapt to changes in the labor market is an important goal of education. As well,on the informatization and industrialization in modern society ,the specific goal need adopt to specific measures and rely on traditional teaching methods can not meeting the requirements of modern higher education for vocational ability training. Searching practical education method will be the endless mode of cultivating sustainable development ability. According to its own situation and different requirement, many counties has been developed a set of new teaching method and pattern which can adapt to the need of society, technology and production, in order to cultivate the key ability as the core, the reform and innovation education teaching methods and patterns. It does well and worth to learn [1].

\section{The Bottleneck Of Practical Teaching}

As a very practically applied subject, Advertising has to adapt to the need for talent market diversity and therefore continuously deliver knowledge updates and theory innovation. Cultivation on basic conduction and innovative skills will not only help students enhance the understanding of theories, but also affect the quality of talents development and competitiveness.

However, at present, many universities' advertising graduates have difficulty in employing. It is 
clearly unfair to blame college education for entering the mass education phase of enrollment and the students' high demands for the conditions of the employment units. The reality is that many of the units which need to advertise professional talent and have good prospects for development is difficult to recruit to meet the requirements of the university graduates [2]. The basic reason is that the teaching of advertising in colleges and universities has a serious deviation, the concrete performance in the following five aspects, which are shown in Fig. 1.

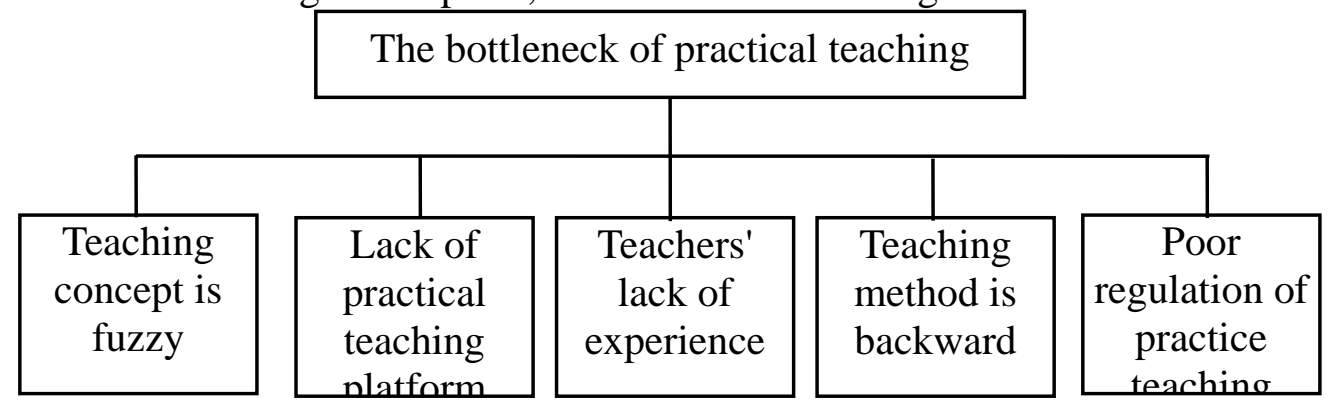

Fig. 1 The bottleneck of practical teaching

Teaching Concept Is Fuzzy.For a long time, it is widely believed that universities should give priority to theoretical teaching, students only need to master the theory, the knowledge application ability and the practical ability can be acquired after the students toward the society. The teaching of advertising theory pays attention to the theory, neglecting the practice, it neglect of the cultivation of students' practical ability, and the practical teaching is a mere formality. Advertising curriculum is unreasonable, lack of pertinence, systemic, teaching contents lack of integrity, operability. Advertising courses have different properties in different universities, subordinate departments also are not identical, some colleges and faculties from different areas and the research direction, and even set up the course according to the existing faculty status, its practical teaching is hard to form a scientific and perfect system.

Lack Of Practical Teaching Platform.The scientific and reasonable arrangement of practical teaching system, need to highlight the cultivation of students' practical ability, the embodiment of professional skills is not out of the test but out of the practice. However, there is no high quality and sharing platform for the practice teaching, not real evaluation through production practice, how can get social approval? To build the practical teaching platform and to have the purpose and target to choose the practice base is the key to carry out the high level practical teaching, and also is the difficult problem which needs to break through in colleges and universities at present.

Teachers' Lack Of Experience.The quality of professional teachers is not high, lack of experience. At present, a part of the universities set up advertising courses in the weakness of the professional strength, many advertising teachers' major is Chinese, management and economics, they don't understand advertising very well. In recent years, although the media or advertising trained teachers' proportion increased gradually, but quite a few is from school to school, mostly good at theoretical description, without practice, have no rich practical experience, lack of necessary perceptual knowledge to advertising actual operation. Some teachers lack of thinking and innovative spirit, scripted, such as analysis of advertising works although is classic, but is incompatible with the rapid development of advertising environment, have no significance to students.

Teaching Method Is Backward.The backward teaching method and means are difficult to meet the needs of the practical teaching. Some schools' advertising teaching is option the teaching with traditional one-way transfer mode which is given priority to classroom teaching, failed to make full use scenario simulation, role, simulation, case discussion teaching method, such as failure to efficient use of multimedia teaching, video and other modern teaching means, The teaching process is dull and boring, it is difficult to mobilize the enthusiasm of the students, it is hard for students to do real hands-on operation.

Poor Regulation Of Practice Teaching.There is no standardized assessment and management measures in the practical teaching area, and it is in a generally state of loose management, lacking 
of the strict limits, which inevitably leads to the blindness of teaching, and it is difficult to guarantee the quality of practical teaching. Teaching researchers have fully realized the importance of practical teaching, they think that practical teaching is the basic link of education in colleges and universities, and it is also the extension of teaching in class and testing, also an effective way to enhance the teaching pertinence and effectiveness of the theories in class. Therefore, it can effectively improve the efficiency of the practical teaching management if we according to the principles and requirements of teaching management, and fundamentally change the current situation of practical teaching in the poor regulation, establish and implement the quality monitoring system of the practical teaching.

\section{The Creative Thinking Of The Practical Teaching}

The creative thinking of the practical teaching includes four aspects, which are shown in Fig. 2.

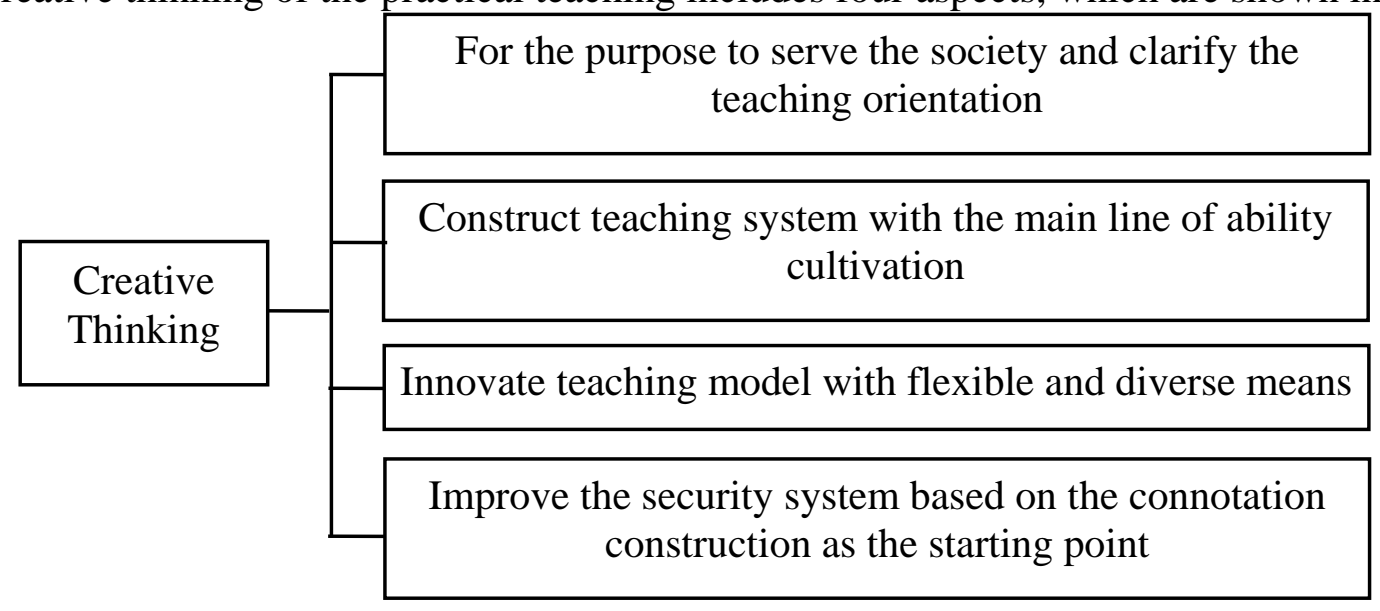

Fig. 2 The creative thinking of the practical teaching

For The Purpose To Serve The Society And Clarify The Teaching Orientation .From a macroscopic point of view, clarify the clear positioning of running school, scientific, unique talent training objectives and educational ideas; from the micro view, a clear positioning of advertising practice teaching is an important premise to train high quality talents in advertising. Transform the education ideas and update their concepts of education, according to the development trend of our country and even the world advertising industry and the development of subject characteristics. Then the fundamental task of education and teaching of advertising is gradually clear, namely the cultivation of people with moral, intellectual, physical, aesthetic development, master engaged in the advertising industry related skills, adaptation of high-quality talents in the development of the advertising industry. Therefore, the goal should be set to "based on the market, social services", to cultivate the professional ability as the core with professional skills as the focus, to adhere to the combination of theory teaching and practice teaching, to increase the proportion of practice teaching so as to make practical teaching throughout the whole teaching process [3].

Construct Teaching System With The Main Line Of Ability Cultivation.Reform and innovation is the breakthrough of education teaching. First advertising industry and enterprises can be understood in-depth from the aspects of advertising practitioners status, responsibilities, work content, work standards, professional knowledge, capacity structure and so on. Fully understand the talent market demand for advertising and analyze jobs and their ability. At last, the professional curriculum system is divided into the theory and practice teaching system based on the ability. According to the teaching outline and the cognitive law of the professional skills and the professional skills,formulate the practical syllabus to guide the practical teaching.

Specific approach: focus on the basis of practical teaching and improve students practical skills while increase the proportion of comprehensive practice, change traditional single verification of the theory of practice and vigorously promote the comprehensive quality training of practice teaching at the same time. Encourage students to innovate in order to provide a space for 
independent study for the student individuality development,that is to say advocating personalized education.

Innovate Teaching Model With Flexible And Diverse Means.To create an environment conducive to students' creativity and practical play inside and outside the class, it is necessary to break the traditional one-way indoctrination teaching method and explore flexible, three-dimensional practical teaching methods to innovate practice teaching mode. For instance, establish the interaction and discussion type teaching mode; inspire students to question, analyze and solve problems; encourage students to actively participate in advertising activities and perceive advertising environment and advertising activities for the purpose to exercise creative ability and practical ability; explore segmented, hierarchical teaching and so on.

Improve The Security System Based On The Connotation Construction As The Starting Point.First is human resources security. The teachers troop is the key to the success or failure of the teaching. At present, the teachers in advertising is lack the age and the structure of the title is irrational; teachers have less or nothing practical experience and advertising background. Advertising teachers should not only have a broad theoretical knowledge, but also a higher professional skills and rich experience in practice. Therefore, it is important to construct double qualified teachers to meet the needs of practical teaching.

Second is the teaching resources safeguard. Quality teaching resources are the basis for improving the quality of practical teaching. To expand the teaching resources and to construct the practical teaching platform are the urgent affairs. On the basis of building the practical teaching platform, develop the university enterprise cooperation and build the large - scale sharing - school practical bases. Establish practice base outside school along with advertising agencies and media advertising department, making it a student internship training in the best place and it can be helpful for students to open up the green channel to jobs in the future.

Third is the management system security. Establish and improve the stability, reasonable, long-term practical teaching management and evaluation mechanism, such as improving and regulating the practical teaching of the examination method and teaching management methods, etc. This is a very weak link in Colleges and universities. The system construction should be strengthened from the practical teaching plan, teaching outline, teaching books and appraisal of the implementation of rules and regulations, etc. Enhance the management and monitoring of the main teaching so as to ensure the smooth implementation of the practical teaching of advertising [4].

\section{The Practical Teaching Mode}

Advertising practical teaching is not social practical in general, but enslaved to educational goal and demand. It must be instructed by teachers, followed teaching rules and principles, and the main thing is to train students' practice ability, making the students acquire perceptual knowledge and basic skill and improving overall quality [4]. In the teaching practices, the following four models are effective, which are also shown in Fig.3.

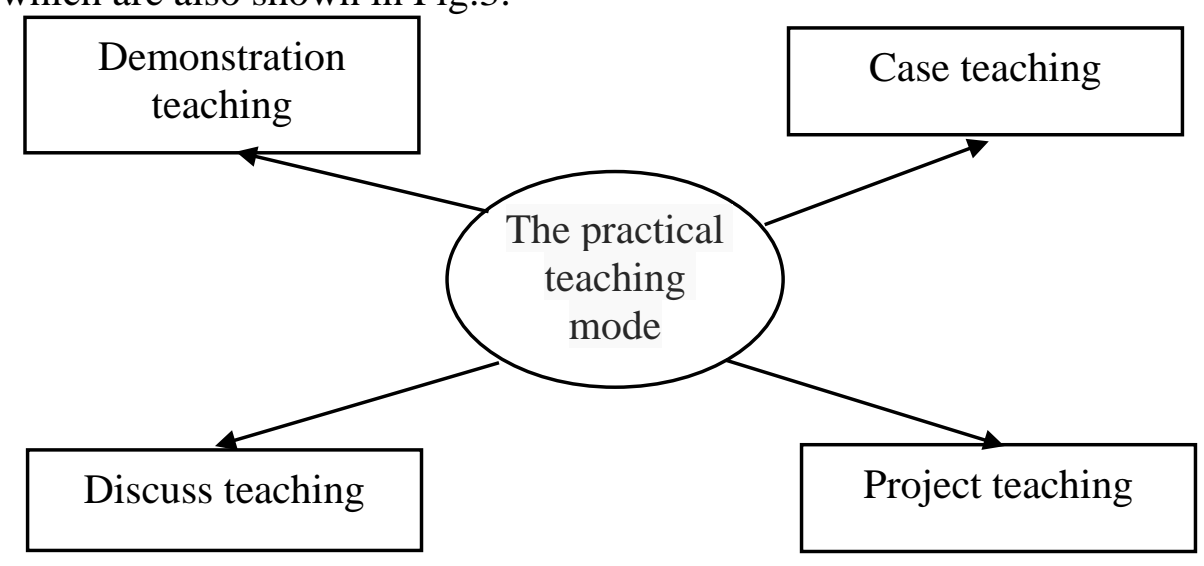

Fig.3 The practical teaching modes 
Demonstration Teaching.Making full use of modern teaching methods such as computer multimedia, showing and explaining the operation process of advertising practice, such as PPT,TV video, multimedia teaching software and so on. This way is usually used with basic classroom teaching activities, and is arranged before or after classroom teaching according to the demand of teaching. Making full use of diagrams, videos, especially the related resources on the Internet to enrich the contents of classroom teaching, making the teaching contents specific, rich,intuitive and understandable to enhance the students' study interest and improve teaching results.

Case Teaching. This is one of the important ways of MBA teaching. Highlighting the idea of student-centered, teacher-guided, case-based teaching and the combination of theory and practice. That is to say in teaching process, students discuss a teaching case with knowledge and method that have learned, put forward a solution, then exchange ideas among students and between students and teachers. The key of case teaching is case design, demanding the cases are real as much as possible, meanwhile have the process of improvements. Cases contain information in all directions, and the answers are diverse. Case teaching is to develop the ability of students' self-learning,cooperative learning and comprehensive analysis through analyzing and solving problems by students themselves.

Project Teaching.First is the situation simulation. This is a practical teaching form applying to one entire real advertising practice, which is built on one advertising business enterprise basic operating cycle and its former relevant data. The main part of this is the internship data simulation, the integrity of the content and the simulation practice guidance and assessment. Second is school practice. It will divided into two situations. One is do advertisement professional ability training and take the real project that adapting to the market needs to the class from the outside. And also, let the student use the knowledge and method and finish an real project design by their own. The project design can finish by one or can also do it by a project team. And it can finish at school or can finish together with the enterprise. The other is operate an advertisement design work studio on teacher's guiding, work with the professional ad team, develop the market activity and operate it marketization. This is also campus college students entrepreneurial creative activities. Many collage organize advertising day and want student to take part in the ad competition. And it does well combining practice teaching with ad competition together. Third is the off-campus practice. Let the students practice external advertising company directly or at base classes to participate in advertising design, operation and management, etc.

Discuss Teaching.After finishing the elementary knowledge teaching, we start seminar-style teaching, focusing on develop the problem-solving ability and creativity. According to the different contents, we could adopt many ways flexibly, such as writing papers, classroom discussion, speech,debate and so on. Teachers lead students intentionally to self-study, discussion, and inspire them to study further and think independently, then teachers make a summary and answer questions.

\section{Conclusions}

In all, in the new era, advertising face much more serious challenges and the needs of talent will be much higher. As the high institution, it need us follow the market tide actively,create much more innovative teaching ideas, attaches great importance to the comprehensive quality of talents and the cultivation of innovative ability, constantly form characteristics to economic and social development. Practical teaching reform and innovation of advertising,will be the only way to improve the quality of talent training and to cultivate high-quality skilled advertising personnel.

\section{References}

[1] Eimear Dolan, Elizabeth Hancock, Amy Wareing. An evaluation of online learning to teach practical competencies in undergraduate health science students. The Internet and Higher Education. Vol. 24 (2015), p. 21-25.

[2] Popescu Elena (Dragan). A Case Study on the Influence of Public Advertising Campaigns in 
Child Education. Procedia - Social and Behavioral Sciences. Vol. 76 (2013), p. 686-689.

[3] Corinne van Velzen, Monique Volman, Mieke Brekelmans, Simone White. Guided work-based learning: Sharing practical teaching knowledge with student teachers. Teaching and Teacher Education. Vol. 28, Issue 2 (2012), p. 229-239.

[4] Chen Haifeng, Tang Peisong, Pan Guoxiang, Cao Feng. Knowledge Represent and Reconstruction by "Fundamentals of Materials Science" Classroom Teaching Mode Reform. Procedia Engineering. Vol. 15 (2011), p. 4305-4309. 